\title{
Operating room greenhouse gas release reduction
}

Pauchard Jean-Claude M.D ${ }^{1}$, Gress Gauthier ${ }^{1}$, Jeanville Stéphanie ${ }^{2}$, Guerquin Lydie ${ }^{3}$, Muret Jane ${ }^{4}$ M.D, Nouette-Gaulain Karine M.D Ph.D ${ }^{1}$

${ }^{1} \mathrm{CHU}$ de Bordeaux - Bordeaux (France), ${ }^{2}$ Hôpital Avicenne-Bobigny (France), $3 \mathrm{CHU}$ de Grenoble - Grenoble (France), ${ }^{4}$ Institue Curie - Paris (France)

\section{Background}

Anesthesiologist are in the front line to reduce environmental impact from professional use of inhaled anesthetics. In France, the reduction of the environmental impact of health care is required by law since the Grenelle act (2009).

Aim: . There are different way to reduce our ecological footprint.
Methods: We performed a search on the ecofriendly practice, datas and clinical trials on PubMed using anaesthetics volatile, atmospheric pollution, ecological footprint gases, fresh gas flow (FGF), inhaled agent as keywords for analysis.

\section{Results}

\begin{tabular}{|c|c|c|}
\hline $\begin{array}{l}\qquad \text { DECREASE FGF } \\
\text { Guthinger \& al calculated an } \\
\text { halogenated consumption } \\
\text { decrease of } 40 \% \text { with FGF } \\
\text { reduction from } 1,24 \mathrm{~L} / \mathrm{min} \\
( \pm 0,74) \text { to } 1 \mathrm{~L} / \mathrm{min} \text {. }\end{array}$ & $\begin{array}{l}\text { USE TCI mode } \\
\text { Tay \& al demonstrated a } \\
\text { reduction of } \mathrm{CO}_{2} \text { emission by } \\
44 \% \text { with this Target Controlled } \\
\text { Inhalation mode. }\end{array}$ & $\begin{array}{l}\text { Well-reasoned use halogened } \\
\text { All inhaled are greenhouse } \\
\text { gases (GHG). Atmospheric half- } \\
\text { life of Nitrous oxyde }\left(\mathrm{N}_{2} \mathrm{O}\right) \text { is } \\
114 \text { years, desflurane } 14 \text { years } \\
\text { and sevoflurane } 1,1 \text { years. } \\
\text { Combined to radiative } \\
\text { properties their } 100 \text { years } \\
\text { global warming potential } \\
\left(\mathrm{GWP}_{100}\right), \text { which determine } \\
\text { their carbon footprint at } 100 \\
\text { years, is } 2540 \text { for desflurane, } \\
298 \text { for } \mathrm{N}_{2} \mathrm{O} \text { and } 130 \text { for } \\
\text { sevoflurane. }\end{array}$ \\
\hline
\end{tabular}

$\mathbf{N}_{\mathbf{2}} \mathbf{O}$ : Medical $\mathrm{N}_{2} \mathrm{O}$ is also an ozone-depleting gas. It represents $0,5 \%$ of global human $\mathrm{GHG}$ emissions. When used with halogenated agents, $\mathrm{N}_{2} \mathrm{O}$ is responsible of more than $50 \%$ of ecological impact. Now, operating room are built $\mathrm{N}_{2} \mathrm{O}$ free.

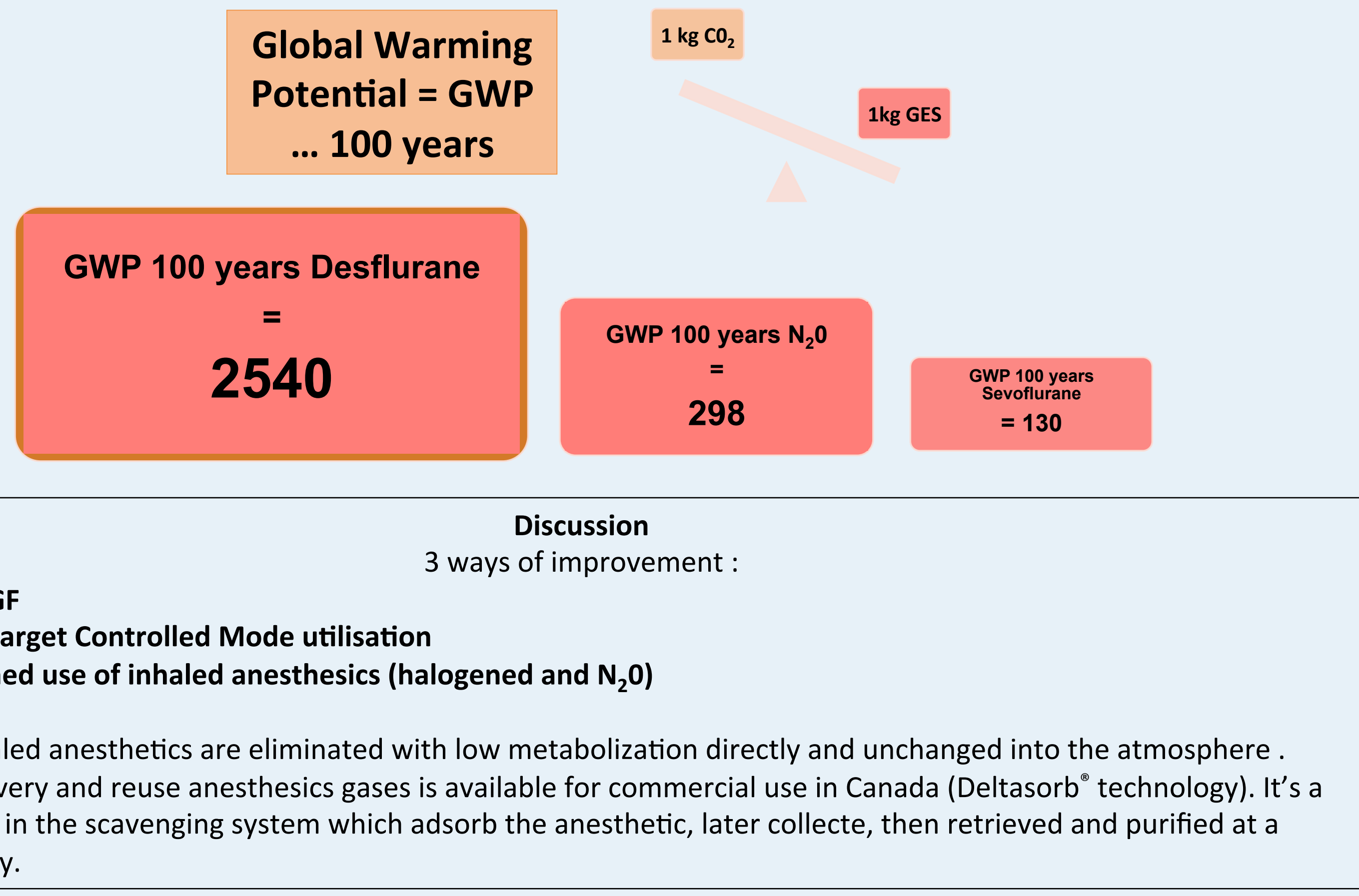

- Reducing FGF

- Increasing Target Controlled Mode utilisation

- Well-reasoned use of inhaled anesthesics (halogened and $\mathbf{N}_{2} 0$ )

Moreover, inhaled anesthetics are eliminated with low metabolization directly and unchanged into the atmosphere System of recovery and reuse anesthesics gases is available for commercial use in Canada (Deltasorb technology). It's a canister placed in the scavenging system which adsorb the anesthetic, later collecte, then retrieved and purified at a company facility. 